The Study of Narrative Speed in Al-zaman al-Mouhesh Based on the Theory of Gerald Brints

Mohammad Ali Azarshab

Professor of the Department of Arabic Language and Literature, Faculty of Literature and Humanities, University of Tehran, Tehran, Iran.

\title{
Tahereh Heidari
}

t_heydari@sbu.ac.ir

Assistant Professor, Department of Arabic Language and Literature, Faculty of Literature and Humanities, Shahid Beheshti University, Tehran, Iran. (Corresponding Author)

\begin{abstract}
Al-zaman al-Mouhesh written by Heydar Heydar portrays the values and traditions of Syrian society. It depicts characters who, in terms of being cut off from past traditions, have become desperate, defeated, incapacitated, atheist, and nihilistic, features which are far from revolutionary characteristics. This article examines the speed of narration in the novel based on the narrative theory of Gerald J. Prince. The objective is to examine the relationship between the time of the novel - measured by seconds, minutes, hours, days, months, and years - with the length of the story text measured by rows, pages, and paragraphs. Although the exact fictional time within which the novel is set is not acknowledged, it takes place within a three-year time span. There is not correlationship between temporal and causal elements in this novel. The unity of place and the main character (narrator) are the elements that give the novel its unity. As the novel feature no orderly beginning and ending, everything is simulteanously intertwined and irrelevant. Likewise, events are scattered. This novel deviates from traditional motifs and techniques including a concern about human beings, ancient Arab relations in the form and context of the narrative, and temporal and spatial structures. The narrative speed of the novel can be analyzed in five main categories. This study suggests that the author has made maximum use of techniques such as interplay between scenes, the phenomenon of alternation and assurance through narrative deceleration.
\end{abstract}

Keywords: Haider Haider, lonely time, fictional art, novel time, Gerald Prince the introduction.

Citation: Azarshab, Mohammad Ali, Heidari, Tahereh; Spring and Summer (2021).

The Study of Narrative Speed in Al-Zaman al-Mouhesh Novel.

Studies in Arabic Narratology, 2(4), 186-216. (In Arabic) 
Studies in Arabic Narratology, Spring and Summer (2021), Vol. 2, No4, pp. 186-216.

Received:July 20, 2021 Accepted: October 17, 2021

CFaculty of Literature \& Humanities, University of Kharazmi and Iranian Association of Arabic Language \& Literature. 


\section{دراسات في السردانية العربية}

الرقم الدولي الموحد للطباعة: • م •

الرقم الإلكتروني الدولي الموحد: rVIV- - IV9

دراسة السرعة السردية في رواية الزمن الموحش على أساس نظرية جيرالد برينتدس

azarshab@ut.ac.ir

$$
\text { محمد على آذرشب أستاذ قسم اللغة العربية وآدابها، جامعة طهران، طهران ، ايران. }
$$

t_heydari@sbu.ac.ir

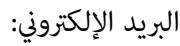

طاهرة حيدري

أستاذة مساعدة، قسم اللغة العربية وآدابها، جامعة شهيد بهشتي ، طهران ، إيران. (الكاتبة المسؤولة)

الإحالة: آذرشب، محمدعلي؛ حيدري، طاهرة. ربيع وصيف (اr.r). دراسة السرعة السردية

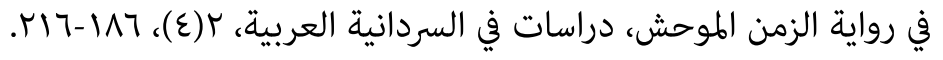

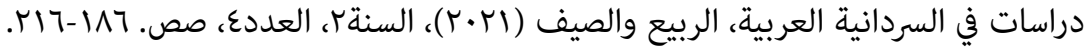

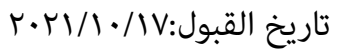

$$
\begin{aligned}
& \text { تاريخ الوصول: • r. r T/V/T }
\end{aligned}
$$

ه كلية الآداب والعلوم الإنسانية بجامعة الخوارزمي والجمعية العلمية الإيرانية للغة العربية

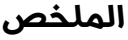

هذه المقالة تدرس سرعة السردية في رواية الزمن الموحش وفق نظرية الناقد الروائي جيرالد برينس. وهدفنا ، هو دراسة العلاقة بين زمان الرواية التي -تقاس بالثواني والدقائق والساعات والأيام والشهور والسنوات - وبين طول نص القصة الذي يقاس تردي بالسطور والصفحات والفقرات . عملت رواية الزمن الموحش من تأليف الكاتب السوري حيدر حيدر، على تحليل قيم وتقاليد المجتمع ورسم ملامح الشخصيات التي 
قطعت إرتباطها بالتقاليد الماضية فظهر عليها العجز و الهزيمة والموت و أفرزت أشخاصا ثوريين وأنانيين وملاحدة وعدميين ومزعجين. وقعت أحداث هذه الرواية في غضون ثلاثة أعوام وما عدا بعض التلميحات الى عدد من فصول السنة ، لن تجد فيها أية إشارات الى الزمن الدقيق الذي يحدد متى وقعت تلك الأحداث. وأما علاقات الزمان والعلة والمعلول في هذه الرواية فهي ضعيفة لكن الذي يمنح الوحدة لهذه الرواية هو نفس الراوي/ باعتباره الشخصية الاصلية فضلا عن وحدة المكان. هذه الرواية ليست لها بداية ونهاية منظمة ومرتبة بل تجد كل شيء فيها متشابكا ولايمت بصلة الى بعضه البعض ـ وكذلك أحداث الرواية، فهي متفرقة. وكما تسعى هذه الرواية للقضاء على الشئون القديمة، هاضي العرب وللانسان العربي وأواصره القديمة في مجالات

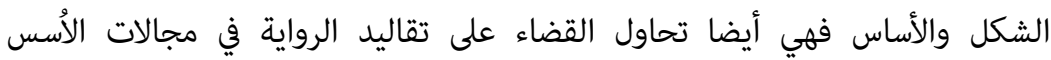
الزمكانية والأحداث والشخصيات. وضمن تمتعها بالمقترحات السردية الكثيرة فإنها إستفادت من المجموعات الخمسية لسرعة الرواية أيضا. وخلال هذا البحث، تجري دراسة سرعة الرواية والتغييرات التي تعتورها من حيث الإسراع والتباطؤ وهذه الدراسة تفيد بأن الكاتب إستفاد بشدة من تقنيات التداخل بين المشاهد، ومن ظاهرة التناوب والتضمين وسبل تقليل السرعة السردية .

الكلمات الدليلة: حيدر حيدر، الزمنالموحش، الفن الروائي، زمان الرواية، جيرالد برينع.

حاز علم (الفن الروائي ) اليوم أهمية كبيرة تبعا لأهمية الاسلوب السردي في النتاجات الأدبية وحظيت مسألة (الزمان) بمكانة خاصة في صميم الرواية. ونحن نشاهد ترابطا وثيقا بين (الزمان) و(السرعة)) مع بعضه البعض وهي من العوامل المؤثرة في الرواية السردية. يقول ريمون كنان :(إن عنصر الزمان لايمثل فقط السِمة المتكررة في الكثير من القصص السردية، بل 
يمثل عنصرا في بناء أسس القصد والنص أيضا ... لأن زمان القصة في معنى التوالي الخَطي للأحداث، يقوم على أساس عقدي وزمان النص لايمثل بعدا زمنيا بل يمثل بعدا حجميا. والنص الروائي في موقع النص، لايمثل سوى هذا المقدار من المدة التي تُنفق على قراءته مجازاً، فهو ليس له توقيت آخر. وما يختص به من بحث حول زمان النص يشهد على ذلك، فالمكياج

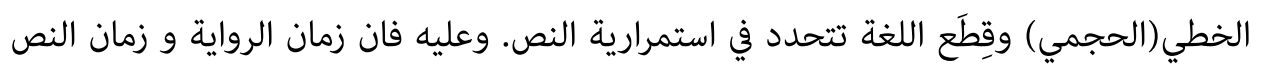
كلاهما زيف و كلاهما شبه زمان. و بهذا الوصف، فإنه مادامت ماهية زمان القصة وزمان النص المقصود مزيفة، فإنها لا تمثل بناء سليما لدراسة الجوانب الاساسية في العلاقة بين (القصة

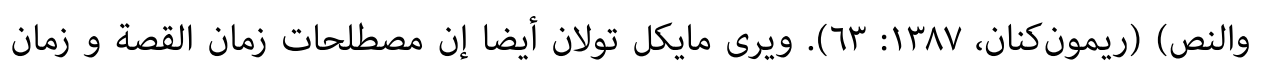
النص ليست لها صفة واقعية بل عقدية تماما إذ أنه مل يحصل فيهما إشارة الى مضي الزمان الواقعي (تولان، سوسا: V^). ونظرا لأهمية عنصر الزمان في أي نص سردي فقد حظي هذا العنصر بالإهتمام منذ القدم

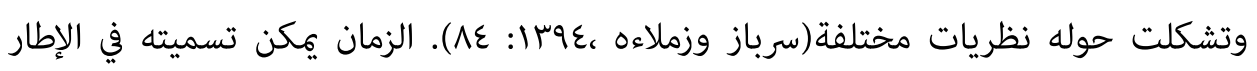
الأصلي للقصة حيث تتطور الأحداث في طولها ويكن التعرف بسببها، على مختلف مراحل القصة ـ فكل قصة تبدأ في لحظة محددة وبعد مرور الزمان الذي قد يكون في ذحو دقيقة أو

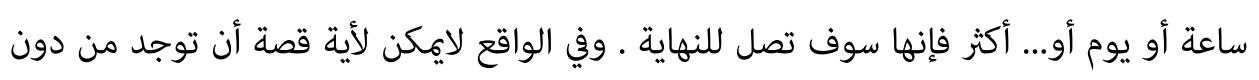
زمان (بارونيان، IN

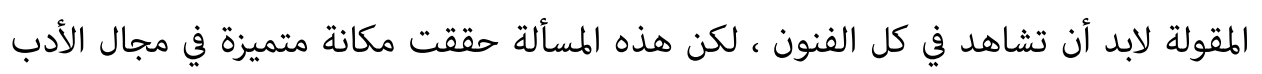

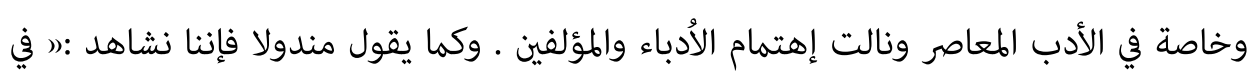
الأدب الجديد ميلا كبيرا نحو مسألة الزمان والكُتاب الذين يختلفون في المسائل الأخرى فيما بينهم ، نجدهم يشتركون في الإهتمام بهذه المقولة ،(مندولا، 199V: • (ץ).

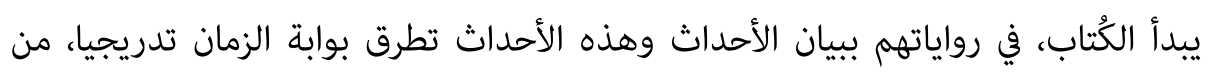
قبل الراوي الذي يعمل ضمن تركيبها مع الأحداث الاخرى ، المى إنشاء عالم متميز للنص • يختار

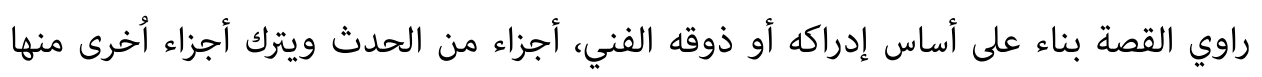
ومن خلال تركيب وتقديم وتأخير زمان الأحداث، يبدع فكرة القصة. لذلك ، فإنه فضلا عن مبدأ 
العليّة، فالذي يساعد على تبديل الحدث الى قصة، يكون له الدور الأساس، والذي يتمثل في

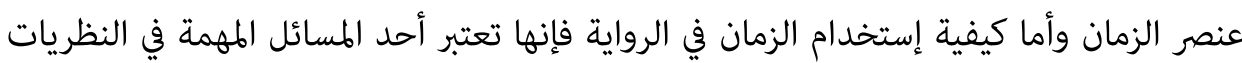
البنيوية التي لها ماض عريق لدى المفكرين والمنظرين. وأما في مجال التوقيت للنص السردي ، فإن جينت هو من أوائل الذين إهتموا بصورة جدية في موضوع الزمان في الرواية ، وقد أعد أشمل بحث للتعارض بين زمان القصة و زمان النص ومع اعتقاده بوجود ثلاثة أنواع من العلاقة الزمانية بين زمان القصة ونظام توقيت الرواية،فقد أجرى مقارنة حول ترتيب الأحداث مع الأجزاء الخاصة بتوقيت الحوادث وكيفية انتظامها في النص السردي ـ ـ وبذلك أصبحت نظرية جينت، المحور الاصلي للنقد البنيوي في الكثير من الآثار الأدبية . قسم جينت مسيرة تناوب القصة من الزمن التقويمي الى الزمن السردي الى ثلاثة مواضيع

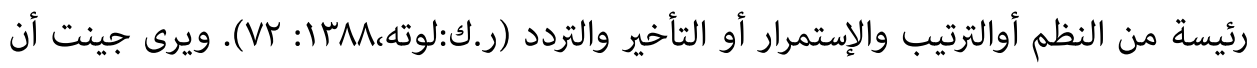
وجود رواية لايطرأ عليها أي تغيير في السرعة، أمر مستحيل. فهو يعتقد بأن الرواية يكنها أن أن تعمل من دون اضطراب، لكن ذلك لن يحصل من دون توقيت أيضا (جينت، 199 I: ؟ • (1). جيرالد برينس أيضا هو من جملة نقاد الرواية فقد تناول برينس الجوانب الجديدة للرواية ومنها مقولة الزمان. فهو يعتقد أن:دالاحداث المنقولة في الرواية يجري تنظيمها لتدور حول محور الزمان)(برينس، اجسا: 79). تقنية وقت الاضطراب، هي من جملة التقنيات البنيوية لكتابة القصة العصرية والتي إستخدمت في الكثير من الروايات الفارسية والعربية المعاصرة. ففي الادب الروائي الايراني والعربي اليوم ، نواجه روايات استخدم مؤلفوها أشكالا معقدة من الزمان تخرج بمسار القصة من مسارها المستقيم، وعملوا على خلق آثار لوقت الاضطراب لايتطابق زمان وقوع الاحداث فيها، مع الزمان الذي جرى اختصاصه في النص. لكن حيدر حيدر مؤلف الزمن الموحش أبدى توجها خاصا لعنصرالزمان. وهذا البحث يعمد الى التعرف على انواع الزمان التي استعملت في هذه

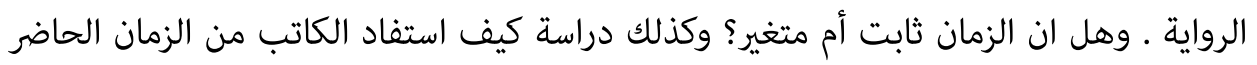
والزمان الماضي القريب والزمان الهاضي البعيد وبين نوع الاستفادة التي إستفادها الراوي من الزمان الحاضر الذي يشكل اساس الرواية وكيف أقحم الأزمنة المختلفة في وسط الرواية وهل 
كان ذلك بشكل منظم ام غير منظم. لذلك ونظرا للإطارالخاص لهذه الرواية وبالإعتماد على

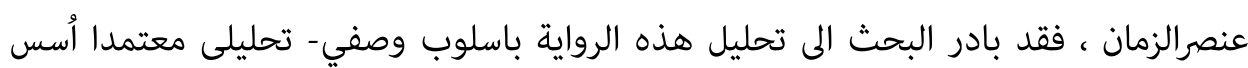

$$
\text { نظرية الرواية لجيرالد برينس. }
$$

وبهذه الصورة التي تم فيها ترتيب الانواع الخمسة لسرعة الرواية وفق نظرية برينس وتم ترتيبها تحت العناوين الخمسة فكان لأجزاء من الرواية التي شهدت حذفا ضمنيا غيرمحدد زاد من التعجيل في حركة الرواية فجاءت تحت عنوان الحذف، واما الاجزاء التي وقف الراوي أمام تسارع الزمان فيها وأدى الى زيادة حجم النص فقد ذُكرت في ذيل عنوان الوقان الوقفة، وأما وصف شخصيات القصة والفضاءات الموجودة في النص الروائي فقد حل بإعتباره عنصر المشهد، وكذلك في الاماكن التي إقتصر الراوي على رواية واحدة لبعض الحوادث التي حدثت مرات عديدة فأوردها مرة واحدة تحت عنوان الخلاصة، وفي النهاية وتحت عنوان التوسعة، التي مل يضمنها تحت موضوع محدد. لأنه ما تكن هناك حادثة جرت سريعا ليُبسِطها الراوي ويوضحها في

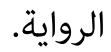

\section{الأسئلة المطروحة في هذا البحث هي كالآتي:}

ا. وقائع رواية الزمان الموحش، كم إستغرقت وعند قياس هذه الفترة من الزمان، أي حجم

$$
\text { من الكتاب تم تكريسه لهذا الغرض؟ }
$$

r. أية خُدع إستفاد منها المؤلف، فجعلت الرواية مستعدة للقبول بمختلف أنواع الفئات

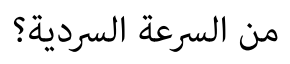

r. ماهي تأثيرات الإسراع أو التباطؤ في نقل الاحداث لعرض أفضل المحتويات وتنفيذ

$$
\text { الخطة؟ }
$$

$$
\text { سابقة البحث }
$$

الكتابات المتعددة لموضوع البحث الموجودة في هذه المقالة بعضها ترجمة وشرح لمؤلفات نقاد الروايات البنيوية من أمثال جينت وتودوروف وريمون -كنان و تولان وعلى سبيل المثال تم شرح آراء جينت بخصوص مقولة الزمان والمصطلحات الخاصة بسرعة الرواية في تركيبة النص

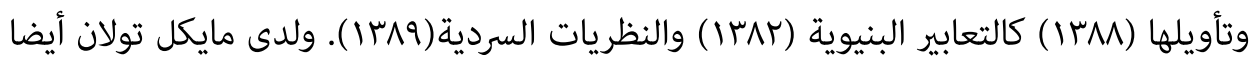




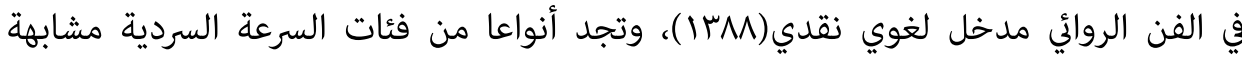
لنظرية السرعة السردية لدى برينس. ويمكن الإشارة الى موارد من هذا القبيل في بحوث الأدب

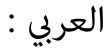
لحميدانى(1991) في كتاب بنية النص السردى من منظور النقد الادبي، وقسم نظام الزمان، الذي فيه إشارة الى موضوع السرعة السردية .

ومرتاض(1991) أيضا أشار الى هذا الموضوع في بحث التداخل بين الأزمنة في كتابه (في

$$
\text { نظرية الرواية). }
$$

والفئة الثانية من البحوث، قامت بدراسة النصوص المختلفة وفق النظريات المختلفة للسرعة السردية. ويمكن الاشارة من بينها الى مقالة "رؤية تحليلية الى سرعة السرد في روايتي (الترهل الشاعر وموسم الهجرة الى الشمال) تأليف بيمان صالحي(شتاء 10·r) وكذلك مقالة (دراسة سرعة السرد في حكايات جُلستان للشاعر الايراني سعدي حسب نظرية جينت)، تأليف وحداني فر (T • (Y) كذلك يككن الإشارة الى سرعة السرد في رواية هؤلاء الثلاثة والعشرين فردا وفق نظرية

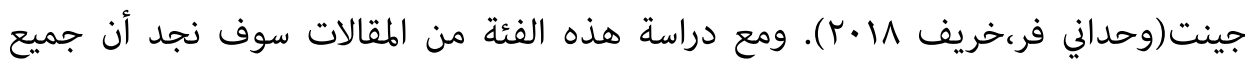
الباحثين الذين اقاموا بحوثهم حول سرعة السرد في الروايات الفارسية والعربية إستفادوا في مؤلفاتهم من نظرية جيرار جينت وتناولوا في تلك المؤلفات قضايا من قبيل العوامل التي تؤدي الى زيادة السرعة السردية والعوامل التي تُفضي الى إبطاء السرعة السردية. ومن بين المقالات الخاصة بالسرعة السردية، يوجد عدد ضئيل ممن استفاد من نظرية جيرالد برينس على سبيل المثال يكن الإشارة الى مقالة ميرزائى و صالحىنيا(10 ·r) وقد إستفاد المؤلفان من نظريات جينت وبارت وبرينس بشكل متزامن. وفي مقالة (دراسة ومقارنة سرعة السرد في حكايتين لكتاب مثنوي معنوي مع مراجعهما على اساس نظرية جيرالد برينس في علم السرد) تأليف محمد

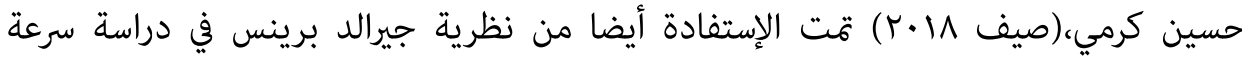
السرد في حكايتين من كتاب مثنوي والاستفادة من مراجعه. تناول هؤلاء الكُتاب هذه المقالة في البداية من مفهوم سرعة السرد وفق نظرية الناقد الروائي جيرالد برينس ومن ثم قاموا بدراسة 
جميع المقترحات السردية الموجودة في هاتين الحكايتين ووضعوها في الفئات الخمسة للسرعة السردية وبينوا حالات التباطؤ والتسارع التي طرأت عليها بصورة دقيقة .

هناك بعض المقالات العربية وجدناها على الشبكة العنكبوتية و نشير إلى إختلاف مقالتنا معها، منها: رضا آنسته و الآخرون( يناير (T.Y) في مقالة تحت عنوان "زمن الخطاب الروائي بين البنية والدلالة في رواية "الزمن الموحش" لحيدر حيدر" التى حصلت على موافقة النشر في مجلة بحوث في اللغة العربية، حاولوا أن يدرسوا أنواع الزمن في الرواية المذكورة دون إعتماد على إنى نظرية خاصة، أما مقالتنا هذه تختلف بما أنها تناقش الرواية المذكورة على نظرية برينتس و هي مختلفة عن المقالة المنشورة السابقة حيث أن مقالتنا تعتمد على دراسة الادوات اللازمة لشرح السردية ووصفها الصريح واستيعاب فعلها وفق هذه النظرية. وتم إعداد بحثين بصورة خاصة حول موضوع الزمان في رواية الزمن الموحش أحدهما أعد في إطار رسالة الماجستير والثاني مقالة:

"بنية الزمن في رواية (الزمن الموحش) لحيدر حيدر"، تأليف وهيبة بن زية وشيماء بوقرة، في جامعة محمد بوضياف-المسيلة، الجزائر وهي رسالة ماجستير. وتتألف من فصلين. عمد المؤلفان في الفصل الأول الى دراسة نظام الزمان، وتقنيات المفارقة الزمنية ، والعودة والقفز الى الامام وفي الفصل الثاني إهتما بدراسة مسائل من قبيل السرعة السردية (الحذف والخلاصة)، والتباطؤ السردي (المشهد والوقفة) وقد استفادا في هذا المجال من نظرية جيرار جينت ـ وعليه مل يتضمن البحث الحاضر اي إستفادة في تلك الرسالة من ملاحظات برينس . زمن الخطاب الروائي بين البنية والدلالة في رواية الزمن الموحش لحيدر حيدر هي الأخرى مقالة أصدرها رضا آنسته في مجلة بحوث في اللغة العربية في جامعة اصفهان عام •r.r.r. وبالرغم من أنه لايتاح لدينا النص الكامل لها في الوقت الحاضر لكن يمكننا أن نعرف من خلاصة المقالة أن كاتبها أراد من خلال الإعتماد على آراء جيرار جينت أن يتوصل الى كيفية استفادة

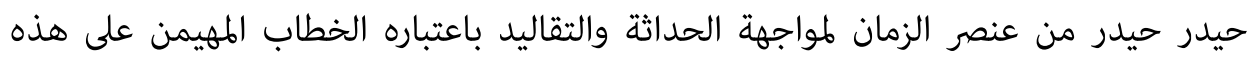


ونظرا للملاحظات السابقة فإن مقولة البحث الحاضر عمدت الى دراسة السرعة السردية في رواية الزمن الموحش بالاعتماد على المقترحات السردية الموجودة في هذه الرواية، ولكن خلافا للبحوث المذكورة أعلاه فإن هذا البحث إعتمد على نظرية جيرالد برينس.

\section{الإطار النظري للبحث}

أحد مناهج الدراسات السردية الأكثر شعبية وقد يكون الأكثر عراقة في المدارس البنيوية. هو منهج عالم السرد البنيوي في الفن القصصي جيرالد يرينس. فهو يعيد قمثيل السردية على الأقل في حدثين أو موقفين في نطاق زمني محدد لن يتناقض أحدهما مع الآخر أو يخالفه

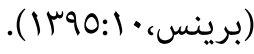

فهو يرى ان المهمة الاولى للفن السردي تتمثل في توفير الادوات اللازمة لشرح السردية ووصفها الصريح واستيعاب فعلها((المصدرنفسه:1(1). ويشير برينس بذلك حول مقولة الزمان في القصة الى موارد من بينها العلاقات بين زمان وقوع السرد والأحداث السردية والفاصلة الزمانية ومدة الزمان والسرعة (المصدر نفسه: ع7-بץ).

و هو يقسم الروابط الزمنية من قبيل زمن وقوع السرد والأحداث السردية الى ثلاثة فئات الرواية المتقدمة والرواية المتزامنة والرواية المتأخرة (المصدرنفسه:بץ) والفواصل الزمنية لفعل السردية والأحداث السردية تكون متغيرة حسب رأي برينس. وقد يكون فعل السردية من الناحية الزمنية منفصلا عن الأحداث السردية أكثر فأكثر (المصدرنفسه:مب). فهو يعتبر تحديد مدة بردي زمن الفعل السردي، وخاصة، إرتباطه بالمدة الزمنية للأحداث السردية أصعب بكثير مما يتوقعه (المصدرنفسه:דب). وهنالك مقولة أخرى يتناولها برينس وهي مقولة السرعة السردية. فهويقول: في باطن كل قصة، من الممكن أن تعرض الاحداث والطواقف التي تصنع أحداث العالم السردية بسرعة أدنى أو أعلى مما هي عليه. ذلك ان طبيعة الاحداث وسرعة عرضها والمواقف التي فيها يصطلح على تسميتها بالسرعة السردية(المصدرنفسه:ه). إن السرعة السردية كثيرة التغيير في الغالب وهذا التغيير في السرعة هو الذي يمنح لكل رواية إيقاعًا معينًا . ونلاحظ ان نظرية برينس في السرعة السردية توسع فيها جينت و ريمون كنان

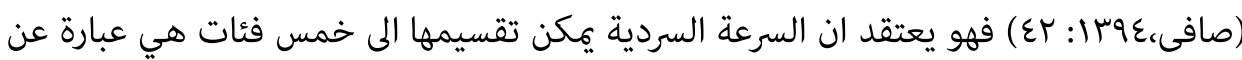


الحذف والوقفه والمشهد والخلاصة والتوسعة ـ وفي هذه الحالة إذا مل يأت على أي ذكر للحدث الذي جرى في أي موقع من الرواية، يكننا عندئذ ان نشير الى وقوع الحذف. وفي هذه الحالة، تحقق الرواية أقصى سرعتها السردية. مثلا اذا مل يأت حيدر حيدر بأي ذكر على احداث مرحلة من أعوام حياة شخصية معينة فإنه يكون قد إستفاد من خصوصية الحذف. وعندما يحصل خرق في المسيرة الزمنية لرواية الزمن الموحش ويتضح وجود فاصلة في تقدم الأحداث المروية نتحدث هناك عن الحذف. وإذا م يحصل أي مقدار من الحذف الزمني في قسم من الرواية

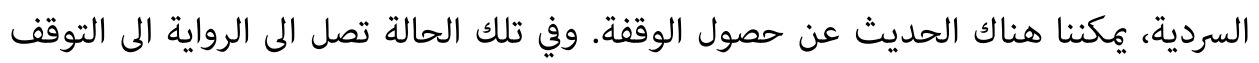
الكامل ـ فعلى سبيل المثال، نفترض ان حيدر حيدر يتخلى في نقل الحوادث المرتبطة بشخصيات القصة ويشير المى موضوعات ليس لها أدنى إرتباط بشخصيات الرواية وعالههم. ان رواية الزمن الموحش تُعرض فيها كسائر الروايات العصرية وقفات كثيرة وذلك لأننا لن نشاهد في أجزاء طويلة منها أي اثر عن الأحداث السردية، وهذه العناصر التي تشبه القصة - لاتكون لها أهمية تذكر. وأما الحد الوسط بين طيفي الافراط والتفريط في الحذف والوقفه، فإنه يتمثل في المشهد. أي أننا نشاهد بين قطعة سردية وحدث يعاد تمثيله (تقريبا) رابطة زمنية معادلة ويكننا إعادة تثثيل الأحداث الى أقصى حد ممكن بصورة دقيقة وعينية . وفي هذه الحالة إذا قام أحد شخصيات الزمن الموحش بسرد قصة حياته، فإن حيدر حيدر يقوم بإعادة قتثيلها بصورة دقيقة وعينية. وفي نهاية الأمر، نشاهده يقع في موارد بين الحذف والمشهد من الخلاصة وفي الموارد التي يقع بين المشهد والوقفة نتحدث فيها عن حصول التوسعة. وفي الاماكن التي نعلم ان الرواية يجري شرحها بصورة كاملة ولكن الكاتب لم يبادر اليها هناك نتحدث عن الخلاصة ففي رواية الزمن الموحش جرى اختصارشديد لحادثة قتل سامر البدوي و ديانا زوجة مسرور واستفاد الكاتب هناك من عنصر الخلاصة . وفي جانب آخر نشاهد الكاتب يصف أحداث عمل محدد في عدة صفحات والحال إنه كان بإمكانه إختصار الحادث بعدة مصطلحات وفي هذه الحالة

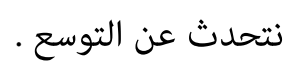

ونظرا للتوضيحات التي تم عرضها سابقا فإن السرعة السردية هي من جملة المقولات التي

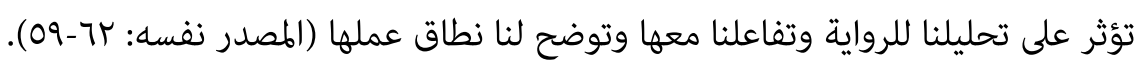


من هو حيدر حيدر ؟ - n

حيدر حيدر أحد كتاب القصة السوريين ولد عام 7سوام. في قرية حصين البحر في محافظة طرطوس. تلقى دراسته الابتدائية في نفس القرية وإلتحق بعدها بكلية التربية في حلب وتخرج منها عام ع019 م. وبعد مضي عامين من تخرجه برزت لديه توجهاته الأدبية ، نشر اولى قصصه بعنوان (المداراة)) في إحدى المجلات في حلب (عميرى، جسعا: I^). وفي بداية خمسينيات القرن العشرين عمت الفوضى في سورية وإنتهزت الأفكار المعارضة الفرصة فقامت بتشكيل التنظيمات والثورات. وكانت الاوضاع السياسية في المنطقة مضطربة أيضا، وبعد الهزيمة العسكرية في فلسطين و تأسيس الكيان الصهيوني. قرر حيدر حيدر بكعية أصدقائه القيام بنشاط نضالي الى جانب مواصلة الدراسة (المصدر نفسه:Ar).

\section{التعريف برواية الزمن الموحش}

تبلورت فكرة تأليف رواية الزمنالموحش بعد هزيمة عامV797 ام ـ وفي بداية عام سلوام. قت كتابة الرواية بتقنية تيار الذهن السيال ـ والرواية ، تصف أشخاصا يعانون من إختلافات فيما بينهم بالرغم من أنهم من حزب واحد. وإجتمع هؤلاء الأشخاص في دمشق على أمل القيام بثورة وتغيير الواقع لكن نهايتهم كانت أن أصيب جميعهم بالإحباط واليأس والهزيمة أو الموت. ويصف شبلي بداية ونهاية هذه الأعوام الثلاثة بهذا الوصف :(رقبل ثلاث سنوات أذكر كيف كان

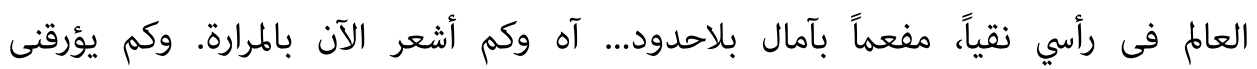

$$
\text { الجُرح)(المصدر نفسه:بسا). }
$$

شبلى عبدالله هو الراوي والشخصية الأصلية في الرواية. تشكلت الرواية من ستة خطوط سردية متداخلة تتقاطع جميعها والشخص الذي يمسك بالخطوط كلها بيديه هو شبلي نفسه. كل خطوط الحوادث واللقاءات تشكلت بين شبلي وأحد شخصيات الرواية مع شخصيات الرواية والتي تتم الإثارة إليها بالترتيب التالي:

راني: يعرفه شبلي عندما كان في القرية وقبل مجيئه الى دمشق ويبقى مصيره مجهولا في

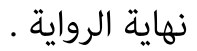
مُنى: تبدأ علاقة شبلي مع منى من بداية الرواية وتنتهي مع سفر منى . 
مسرور و ديانا: تعرف شبلي على كليهما بعد وصولهما الى دمشق بعدة أشهر .

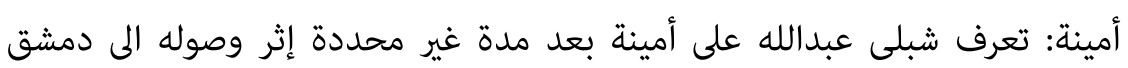
وتنتهي علاقته بها عندما غادرت أمينة بيته وسافرت مع شاب آخر . سامر البدوي: إنه شاعر مثقف تعرف عليه شبلي بعد فترة غير معروفة من وصوله الى دمشق واستمرت العلاقة بين الرجلين حتى قتل سامر . وائل الاسدي: تعرف شبلي على وائل بعد سفر راني الى بيروت لمواصلة الدراسة ، واستمرت العلاقة بينهما حتى زمان تعرض وائل لحادث أدى المى مقتله . بداية الرواية، اعلان بداية الثورة وإنتفاضة الفقراء والمضطهدين الذين يرى الراوي نفسه أنه في مقدمتهم. وهو يشير الى هذا الأمر في موضعين من الرواية فضلا عن مطلعها:"(بعد أن تحولت دمشق الى محطة ثابتة للذين هاجروا من حيفا وانطاكية، والذين قدموا من الصحارى و الجبال فجر ذلك اليوم)((المصدر نفسه:IV) والاشارة الثانية في الزمان الذي يودع فيه شبلي عبدالله أمه مها قاصدا التوجه الى الشام :(و فى ذلك الصباح والفرح قمر ساطع ينير كل سهول النفس و منحدراتها، سألت تلك الأم الوحيدة : الى أين تتركنا وترحل؟وفى ذلك الصباح أجابها فرحي: الى الشام)، (المصدر نفسه:جس). ويمكن بيان حوادث كل فصل من القصة ايضا حسب الترتيب التالي :

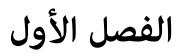

- - بداية الثورة وبزوغ الشمس على الفقراء وهجرة الكثير من القرويين الى دمشق(صه)وكان سفر مُنى وغيابها أشبه بالرؤيا (التي تحدث في نهاية الرواية لكن الراوي أوردها في البداية (ص•|) - اطلاع شبلي على ماضي منى وفي المقابل تعرف مُنى على ماضي شبلى(صب| ا-1|)ذهاب شبلي الى بيت مسرور(ص10)- سفر الراوي بكعية منى بالاوتوبيس الى البيت الجديد(ص^|)-مرور لقاءات الراوي مع منى في البيت القديم في حيالسبكي(صوا()- لقاء الراوي مع راني في الجمعية الصيفية (النادي الصيفي) المكان الذي يطلب فيه من راني تعريفه على المثقفين (صجr)- التجوال الليلي مع راني في القرية، المكان الذي يبدو فيه راني سروره لأن الثورة توشك عل الإندلاع وهو يطلب من شبلي أن يحافظ على هذا السر تبعا لتعليمات الحزب 
(ص7r)- يقوم شبلي وراني بعد خروجهما من النادي بالتجول في الشارع بعدها يتجه راني الى بيت شقيقه ويذهب شبلي الى بيت أمينة(زوجة أيوب السرحان). لقاءات راني و أمينة تستمر (حتى عندما يكون زوجها الخمار أيوب السرحان موجودا في البيت) (عَ-وץ). راني يُعرف شبلي على الشاعر سامر البدوي فتستمر اللقاءات بين الرجلين في النوادي واماكن شرب الخمور(Or)وفي نهاية هذا الفصل يصف الراوي العلاقات بين شخصيات الرواية هكذا :(أمينة تريدني وأنا أريد جسدها. أيوب السرحان يُريدها وأنا أريد مُنى، ومنى تريد ميسالينا. وانا وأمينة وأيوب السرحان ومنى وميسالينا، ندور كالدراويش فى حلقات ذكر حول جدار الزمن المرفوع بيننا

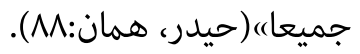
الفصل الثاني - راني يذهب الى بيروت لمواصلة الدراسة في مرحلة الماجستير (ص^||)- يتعرف الراوي على ضابط الاستخبارات وائل الاسدي ويقيم كذلك علاقة مع هدى خليلة وائل وبنت عمها ناديا. يتحدث وائل عن والده الذي أصيب بجروح في عام ^عال ام. تتكرر لقاءات الراوي مع وائل وهدى وناديا. يتوجه هؤلاء للسمر كل ليلة في الصحار (98-105) - الحديث عن ذكريات السفر مع منى بالحافلة الى ساحل البحر(ص7|1)- لقاءاته المختلفة مع سامرالبدوى ووائل الاسدي ومسرور و ديانا (صعr|)- يتذكر الراوي أيام طفولته وتعامل والده غير اللائق مع

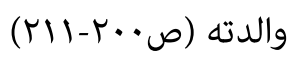

\section{الفصل الثالث}

-راني يعود من بيروت ويسأل شبلي عبدالله عن مُنى وأمينة ،الراوي يقول لراني: منى سوف تسافر وأمينة تتمنى أن يتزوجها.ويبدأ التجوال الليلي مع راني في أزقة دمشق ويتذكر خلالها الراوي تجربة سامر البدوي المريرة مع زوجته، وإشفاق ديانا على زوجها مسرور كما يتذكر أيوب

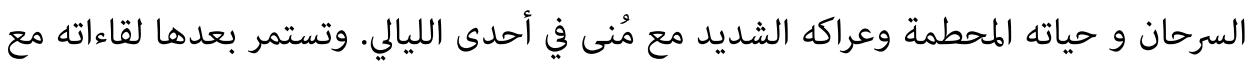

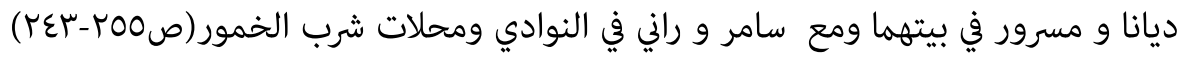
- ويتذكر الراوي مجددا الخيمة البحرية وفترة طفولته و موت والده (صVץr) 


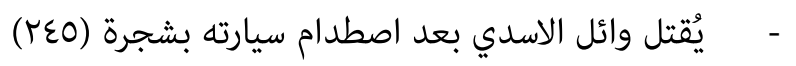

-بعد عراك شديد مع أيوب السرحان تتركه أمينة وبنتها سمية (rON)

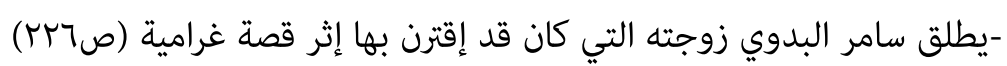

الفصل الخامس

سامر البدوي يتعرض للقتل (صسM)- شبلي يذهب الى بيت مسرور ويشارك في ضيافة ويقيم علاقة مع ديانا، وعندما يشعر مسرور بخيانة زوجته ديانا يقتلها(صV9) يلهوص يبقى شبلي

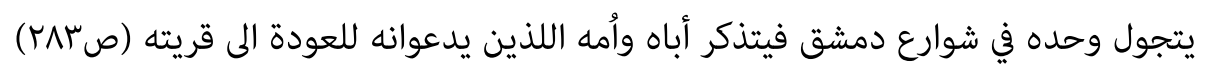
ومثلما نشاهد، فإن هذه الرواية حافلة بالذكريات والخيال والتحليلات النفسية للشخصيات، وفيها إشارات الى تجارب وتأملات وتعرف على الذات وعلى الشخصيات الثورية، وكذلك تشتمل

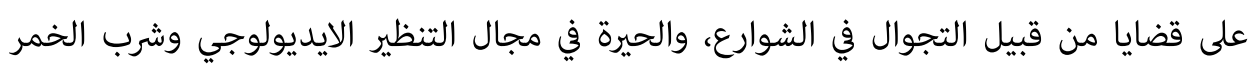
والعلاقة بالإناث. ويرى الراوي كل شخصيات الرواية ثوريين مقهورين ويعتبرهم جزءا منه

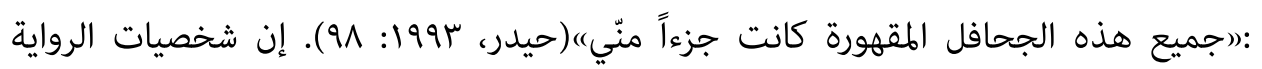

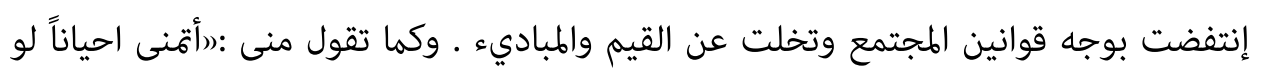

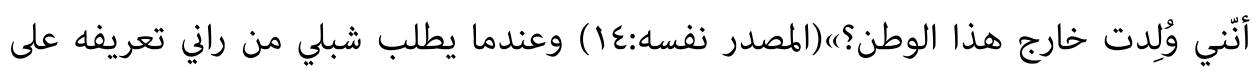
المثقفين يقول له راني:(سريعاً ما تملّهم. أنانيون و عدوانيون و منقسمون. دعك منهم)، (المصدر نفسه: 7r). وأما شبلي فإنه يصف نفسه وراني بهذا الشكل:((شارع وشارع، ثم آخر وآخر. نسوح

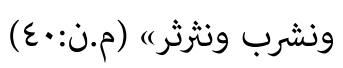

\section{دراسة سرعة السرد الروائي في رواية الزمن الموحش}

الزمان التقويمي لرواية الزمن الموحش، ثلاثة أعوام والحجم التقريبي للرواية لـاس صفحات.

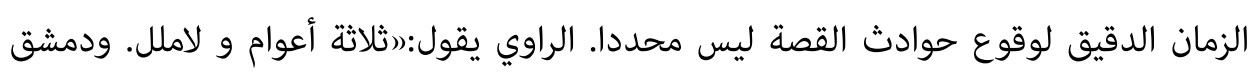
سكينة تنحلّ فى النفس والبدن، يختطف الذكريات فتكاد تنسى كلّ إبن أنثى كوخه الذي لِّي هجره)( المصدر نفسه:101). يذكر الراوي الفصول التي حدثت فيها الحوادث في القصة بهذه

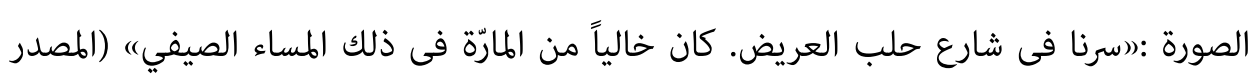


نفسه:1اعV). (اتحت شجرة صنوبر فى حديقة المزرعة،نرقي. فى السماء الربيعية قمر دمشقي مضيء...)( المصدر نفسه:IVI). ((حدث ذلك فى غروب خريفي)( المصدر نفسه:(19)). وعليه فإننا نلاحظ خلال القصة أن الراوي أمضى الفصول الثلاثة الصيف والخريف والربيع في دمشق . في هذه الرواية نشاهد بصورة عامة عدة أنواع من الزمان في حالات تغيير مستمرة : زمان الحال ،الذي يأتي فيه الراوى شبلي عبدالله الى دمشق على أمل قيام الثورة لكن الثورة تفشل لعدة أسباب مختلفة، وزمان الماضي القريب الذي يتذكر فيه ذكرياته مع الافراد الذين تعرف عليهم في دمشق وزمان الماضي البعيد، وهو الزمان الذي يتحدث فيه عن طفولته وذكريات البيت الصحراوي. وعليه فإن هذا الراوي إستفاد من زمان الحاضر الذي يضع فيه أساس روايته، وفي أواسط الرواية يعود بصورة غير منظمة الى الزمان الماضي.وأما الزمان التقويمي وعدد إندان صفحات هذه الرواية فقد أدرج في الجدول التالي أدناه : الجدول (1): الزمان المختص في الرواية المذكورة

\begin{tabular}{|c|c|c|c|}
\hline والصفحات & والأيام & بالشهور & الزمان المختص \\
\hline m. & $1 \cdot \Lambda \cdot$ & T & في كل الرواية \\
\hline
\end{tabular}

الإضطرابات الزمانية للزمن الموحش من الصعب ترتيبها فهذه الرواية معقدة جدا من حيث ظروف الزمان. خاصة إنه أحيانا ومع عدم ملاحظة الاشارات الزمانية الواضحة فإننا نجد اشارات متناقضة بل ومضللة ويحس القاريء إنه قد ضاع بين الأزمنة ـ وفي الكثير من لقاءات الراوي مع سائر الشخصيات، تنمحي المعالم الزمانية بالشكل الذي يصعب فيها على القاريء تحديد الظرف الزمني • وفي أقسام عديدة من هذه الرواية نواجه أجزاء مقطعة تخص أحد خطوط القصة

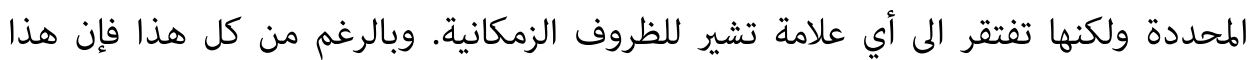
البحث سعى لقياس سرعات السرد الخمسة وفق نظرية برينس في هذه الرواية ودراسة علل التفاوت في السرعة في أجزائه المختلفة. 
الحذف زاد من سرعة السرد في الرواية وقلص حالة الملل التي تنتاب القاريء ما يدفعه الى

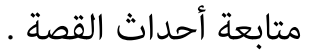
في الزمن الموحش نواجه زمانا دائريا لا يتقدم الى الامام بصورة تراتبية. فالراوي يصور لنا لقاءاته مع سائر شخصيات الرواية في النادي، وفي بيته او في بيوت تلك الشخصيات. وفضلا عن هذا، فإن الراوي يتحدث عن جولاته مع إحدى الشخصيات في الشارع ـ وهذه اللقاءات ليست يومية وإنها قد تحدث أحيانا في فترات متباعدة وعليه فإننا نجد في هذه المقاطع من الرواية، حصول حذف ضمني غيردقيق من الناحية الزمنية.فعلى سبيل المثال يلتقي الراوي أمينة أحيانا

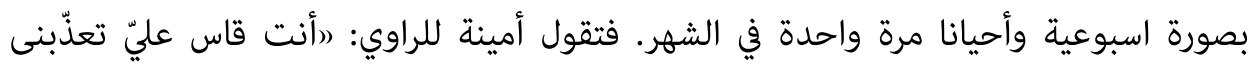
بغيابك الطويل)، (المصدر نفسه:Vع). ومثلما نشاهد فإن الراوي يختار من الزمان التقويمي الطويل، لقاءا مع أمينة بصورة إنتقائية ،ثم يحذف باقي الأحداث في هذه الفترة الزمنية. وفي مكان آخر تقول أمينة:(فى الليالي تأتي كطائر غريب. لحظات وتمضي. أسبوع أسبوعان. شهر احياناً ولا أراك. لا أعرف عنك شيئاً. حرام

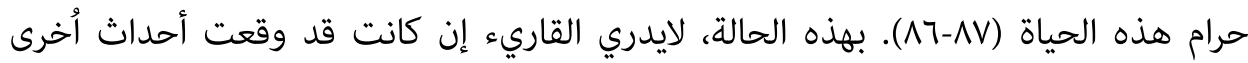
خلال هذه الفترة أم لا ؟ وهل كان لدى شبلي لقاء آخر مع سائر الشخصيات أم لا ؟ فالرواية لا تعطي بذلك أية إشارات من حيث الزمان. فعلى سبيل المثال يقول مسرور مخاطبا شبلي (الراوي):(ملعون دينك مضى اسبوعان و مل نرك)( المصدر نفسه:10). واما الراوي فيتحدث أيضا عن لقائه مع راني قائلا:(رلى شرفة بيت أخيه كنا نسهر. تحتنا الشارع وفي مواجهتنا عمارات متلاصقة (المصدر نفسه:Y

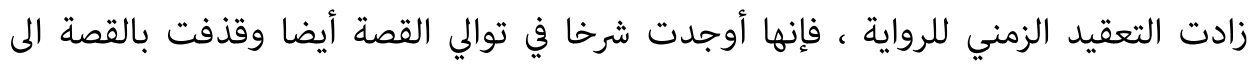
الأمام ـ كذلك فإن مقدارا من الزمان، الذي وقعت فيه الحوادث ملم يورد بأي صورة من الصور وه ينعكس في نص الرواية. فعلى سبيل المثال يقول الراوي في إحدى لقاءاته مع مُنى:»كان

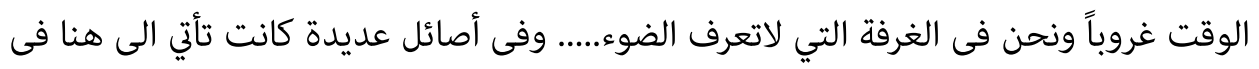

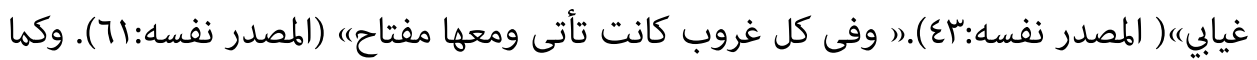
نشاهد فإن الراوي يختار عدة لقاءات ويرويها ويقتصر على لقاءات محدودة مع كل شخصية 
وبالنتيجة تحصل حذوفات ضمنية غيرمحددة تزيد من السرعة السردية. ومن وجهة نظر حيدر حيدر، فإن للحوادث والشخصيات أهمية أكبر لكنه إستفاد أيضا من الحذف لكي يجعل الحوادث أكثر وضوحا وبالتالي يشجع المخاطب أيضا على مواصلة القراءة .

الوقفة

وفي هذه الحالة، تصل الرواية الى التوقف التام. وتتوقف حالات الوصف التي توقف بدورها

تسلسل الاحداث وتدفع الحوارات وهي من عناصر الرواية الى التوقف أيضا .

ويعد عنصر (الحوار) أكثر عناصر هذه الرواية أصالة لدرجة أنه يمكن إعتبار هذه الرواية

بانها رواية الحوارات. "يمثل الحوار الجزء الذي لاينفكّ عن الاشخاص وهو يعد من أهم عناصر

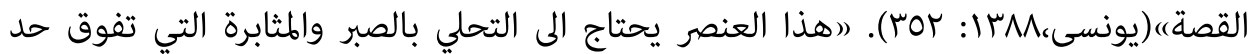
التصور والهارة العالية حتى يكتب له النجاح. وصِدق الحوار وأصالته هي مزاوجة لطيفة للواقعية الناتجة عن النمطية)(ميريام،•^با: V•0). ولقد إستفاد مؤلف رواية الزمن الموحش كثيرا من هذا العنصر للدفع بروايته الى الامام ـ ان عنصر الحوار يمنح الرواية اساساً تعجيلا ثابتا لكننا نجد في اجزاء من هذه الرواية ، ان الحوارات تقلل السرعة السردية فيها كثيرا. وشاهدنا في أول حوار في هذه الرواية حوار للراوي مع مُنى:(هل قلت نفترق؟- أجل...أنت تعلم أنني

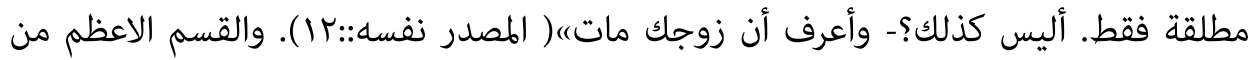
الحوارات الواردة في هذه الرواية لا علاقة لها بحبكة القصة وقد أدت الى تقليل السرعة السردية للرواية. فعلى سبيل المثال: يدخل الراوي(شبلي عبدالله) بيت مسرور من غير دعوة ويجلس

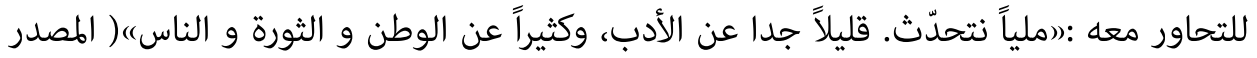
نفسه::7 (1). كذلك نشاهد في هذه الرواية اول نقاش جدي يحصل بين راني و شبلي حول الفرد والحرية بهذه الصورة:(وفى ذلك الغروب ندخل فى اول نقاش حاد حول الفرد و الحرية، حول الثورة والمجتمع، حول التنازلات الخاصة و العزلة وبداية الانهيارات)( المصدر نفسه:^ץ). ويرى الراوي خلال حواره مع راني ان المثقفين يطلقون كلاما فارغا فيقول:دالمثقفون هنا كطحالب البحر... ماذا نقدّم نحن. خمر. ثرثرة. تحليلات اندفاعية. حفرٌ مضنٍ عن الحرية و المرأة وأشياء اخرى لاتطال)( المصدر نفسه:Vr). وعليه فان الكثير من الحوارات الواردة في هذه الرواية ، 
والتي جرت بين هؤلاء المثقفين ، ليس لها تأثير يذكر في حبكة القصة الأصلية. وأما موضوع

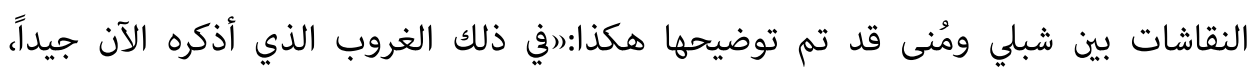
اجتاحنا حوار عقلي حادّ ومرير حول الحرية والهجرة واللوثات الداخلية التى راكمتها سنوات الطفولة والاضطهاد والارث)( (المصدر نفسه:عع). دراسة هذه الحوارات والاتصالات المتبادلة بين شخصيات الرواية، والفضاء الذي يعيشون فيه وكذلك حياتهم الاجتماعية تكشف للمخاطب، واقع فترة زمنية خاصة. ويكن ترتيب حوارات هذه الرواية بالصورة التالية أدناه: - الحوار مع منى في الصفحات:

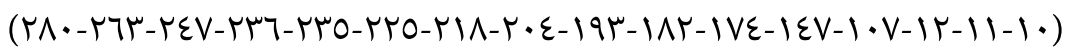

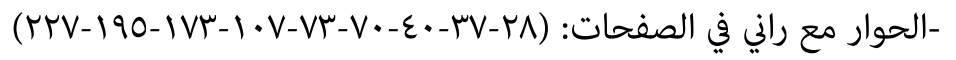

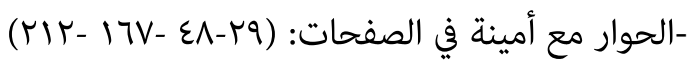

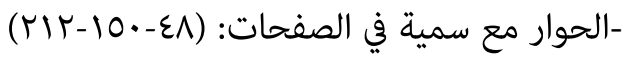

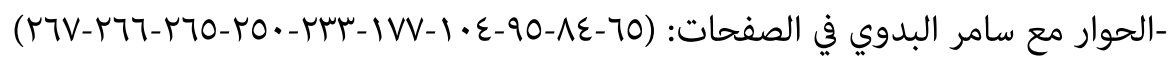

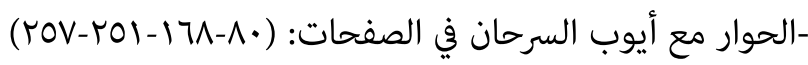

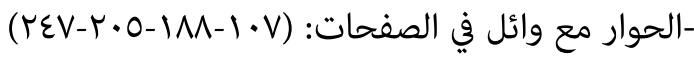
-الحوار مع والد وائل في الصفحة: (T • ( ) -الحوار مع هدى و ناديا في الصفحة: (V) (I)

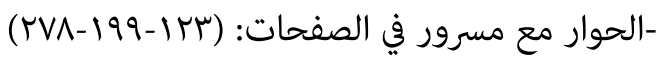

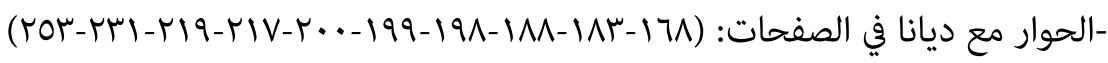
حوار شبلي مع والده في الصفحتين: (rNYrOr) -حوارشبلي مع والدته في الصفحة: (بری) و فضلا عن اعتماده على عنصر الحوار في روايته فقد أدخل حيدر حيدر آراءه أحيانا في النص الأصلي للرواية أيضا ـ وقد إنعكست تلك الآراء أحيانا بشكل مباشر وأحيانا أطلقها على لسان شخصيات القصة (بشكل غير مباشر) وفي كلتا الحالتين يستبعد المؤلف، النص الأصلي للقصة 
ويتحدث عن أشياء لاعلاقة لها بعام القصة ـ فعلى سبيل المثال: يقوم شبلي مع بداية الرواية ، بييان آرائه بشأن مختلف المسائل والني يكن شرحهاء كالتالي: - آراء المؤلف في المثقفين (YV-II)

ـ آراء المؤلف في الرجال العرب وافاط تفكيرهم حول المرأة وضحه على لسان (مُنى)" (rع)

-تعريف المؤلف للانسان الثوري: (عع)

-رؤية المؤلف للزمان: (7)

- رؤية المؤلف حول العرب: (oV)

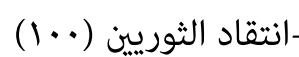

- آراء المؤلف في الوطن (سّ • (1)

- آراء المؤلف إزاء العرب الذين ودعوا الوطن (IrV)

-رأي المؤلف في العرب محكوم بالدين والوراثة (•rاء)

-رأي المؤلف في وحدة الوجود والثورة (اسا)

-رأي المؤلف في المثقفين يطرحه على لسان ديانا (Tسا)

ـرؤية شخصيات الرواية حول المرأة (سبا)

-ايمان المؤلف برؤية فرويد (جسا)

- آراء المؤلف بالقوانين الشرعية لقدماء العرب(IIVV)

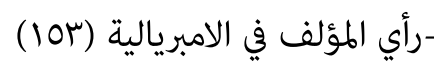

ـ- آراء المؤلف حول فلسفة الحياة يطرحها على لسان وائل (ع7)

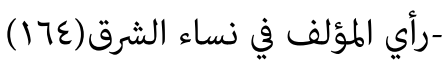

-رأي المؤلف في (الارض) ينقله على لسان والده (IVo)

-رأيه بالجيل الجديد نقله على لسان والد مسرور (199)

- آراء المؤلف حول الله والانسان والعام (roo)

- إيمانه بالعرب (rON)

-إيمانه بالقضية الفلسطينة (ع7r) 
في هذه الأمثلة التي ذكرت نلاحظ أن المؤلف ملأ فضاءات كبيرة من النص بآرائه الخاصة وتسبب بهذا الاسلوب في تقليل السرعة السردية للرواية. ذلك أنه أوقف تقدم عنصر الزمان وتسبب بزيادة حجم النص ـ تبيين الآراء ،يعيق حركة الزمان ويتقدم بالرواية في العَرض ويمنع حصول حركة في الزمان الى الأمام ـ وفضلا عن تقليل سرعة السرد فإن الاستفادة من هذا العنصر يوفر فرصة للقاريء ليتعرف من خلال إبداء هذه الآراء على الكثير من أبعاد شخصيات القصة الوجودية وكذلك ينتبه الى أفكارها وآراءها فيتابع مجريات القصة بشغف. وفاذج هذا الموضوع تهري من رواية الزمن الموحش كثيرة وهي لاتحتاج الى التحليل . (المقارنة بين الشخصيات) هي الأخرى من جملة الخدع التي إبتدعها المؤلف لإبطاء السرعة إنهاء

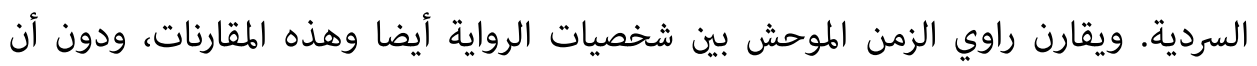
تلحظ الزمان، لن توجد أية حركة في الرواية؛ بل كل ما تفعله هو زيادة حجمها فقط. وفي مثل هذه الموارد تصبح سرعة السرد، بطيئة أو حتى ثابتة. أجرى مؤلف رواية الزمن الموحش مقارنات كثيرة جدا بين شخصيتي الرواية أمينة وديانا مع منى .

\section{المشهد}

المشهد، ويمثل العلاقة في مواجهة الزمن بين قطعة من الرواية والحدث المعاد تثثيله وعرضه. ״ (طول مشاهد القصة، هي التي تحدد الإيقاع؛ أي المدة التي يككن التوقف في مكان وزمان محددين)(مكلى، يمنع تقدم القصة. وهذا الموضوع يبين الاختلاف الثابت العميق (وصف الحالة)، التي تقف في جانب بينما تقف ديناميات السرد القصي من جانب آخر)((آدام- ميشل، سربا: 09). إن وصف شخصيات القصة والفضاءات الموجودة في النص السردي يدفع للاستفادة من عنصر المشهد ويمكن الاشارة الى ناذج منها في رواية الزمنالموحش حسب الترتيب التالي أدناه :

-وصف الثوار (99)

$$
\text { -وصف مُنى (Tسr- }
$$

- موف غرفة مسرور(10)

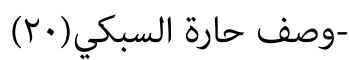




$$
\begin{aligned}
& \text {-وصف دمشق وأهلها ( ( } \\
& \text {-وصف الليل والتجول ليلا في دمشق (ro) } \\
& \text {-وصف نادي المثقفين (Tr) }
\end{aligned}
$$

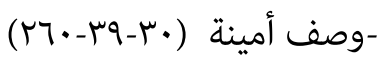

$$
\begin{aligned}
& \text {-وصف الزمان الدائري المتكرر (ع7) } \\
& \text {-وصف المؤلف نفسه والعرب (•^ا-7اع|) }
\end{aligned}
$$

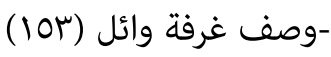

$$
\begin{aligned}
& \text {-وصف والد وائل (10) } \\
& \text {-وصف المرأة (r7) } \\
& \text {-وصف ديانا (س7 ال-110) } \\
& \text { - وصف الزمن العربي (TOO-rTV-177) } \\
& \text {-وصف الحوادث التي جرت ل هدى وتعذيب الرجل المجرم (عجr) } \\
& \text {-وصف مشهد موت وائل (جع (ب) } \\
& \text {-وصف ايوب السرحان (rov) } \\
& \text {-وصف بيت مسرور وضيوفه (YVo) }
\end{aligned}
$$

نظرا للأسلوب الواقعي لرواية الزمن الموحش، يتضح لنا ان الوصف الذي اتبعه المؤلف في الرواية هو من النوع (العيني). فقد سعى المؤلف في الاقسام المختلفة للرواية الى إعادة تثيل الحوادث بصورة دقيقة وعينية الى أعلى حد ممكن (برينس، نفس المصدر:09). "(يلجأ الروائي الي الوصف من اجل ابطاء ايقاع الزمن ليشعر القارئ بالمعاناة التي يشعر بها الشخصيات،

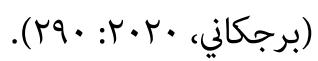

ومن الموارد الاخرى التي سعى المؤلف لتسجيلها كلمة كلمة هي الكلمات التي كان يرددها مع نفسه ـ فقد إستفاد من أقواله ذاتها مما جعل المخاطب يزداد تشوقا لمتابعة أحداث الرواية. وقد عرض المؤلف فاذج بديعة من اسلوب (الإستفادة من أقواله) في الصفحتين 19 و الحب. ففي هذه النماذج ، يعرض الراوي أقواله ويخاطب بها نفسه ويبين للقاريء أن هذا العمل يكون 
مؤثرا في مساوات سرعة الحدث مع قطعة من الرواية. ويتحدث في الصفحة 19 حول الزمن الماضي وفي الصفحة البا، يتحدث مع نفسه بعد مهاجرة أمينة . (الماضي) أيضا من جملة العناصر التي استفاد منها مؤلف رواية الزمن الموحش كثيرا فهو يُعرف بذلك مخاطبه على الاحداث الماضية و العهود المنصرمة لاشخاص القصة وفترة الطفولة والشباب. ولأسباب مختلفة تخص الراوي، من قبيل ردم الفجوات النصية المحتملة التي لايكن للرواية فك رموزها في الزمن الحالي، وظهور شخصيات جديدة في القصة، وتكميل الحكايات و... غيرها إستفاد الراوي من عنصر (الماضي) (يعقوب، ا.. r: r7). وإننا نلاحظ ان عنصر (الماضي) يهيمن على شخصيات رواية الزمن الموحش ـ فهؤلاء لا يمنهم الخلاص من الماضي. ذلك ان إرث الماضي يهيمن على هؤلاء وهو سبب هزائهم. فما ورثوه كان القمع الممتد لفترات طويلة على المستوى الفردي والاجتماعي والسياسي. ولهذا السبب تحولوا في حياتهم الشخصية الى أناس غير فير فئرئ متزنين سرعان ما يواجهون الهزيمة على مستوى الثورات الكبيرة. هؤلاء يعيشون في زمن يتقدم سريعا الى الأمام لكن العرب جامدون من دون حراك ـ خطوط القصة تعرضت للتقطيع بسبب الاعتماد على عنصر (الماضي) بينما نشاهد تكرر في الأحداث. وهذا الأمر يدخل القاريء بنفس الحيرة التي تعانيها شخصيات الرواية. ومن جملة عناصر (الماضي) يمكن الإثارة الى الموارد التالية

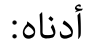

-ماضي منى في القاهرة، قتل زوجها وبقاء بنتها ميسالينا هناك (II)

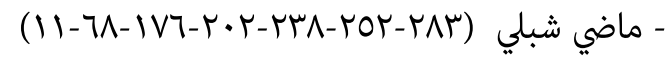

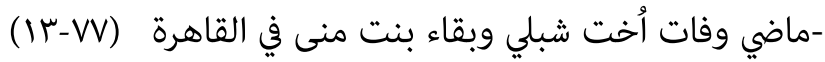

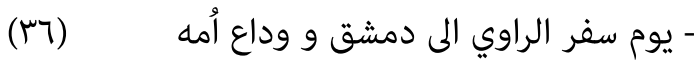

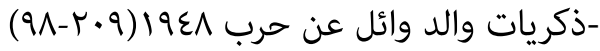

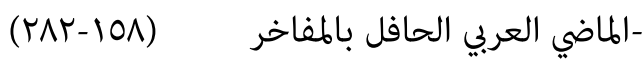

-ماضي التاريخ الاسلامي و طفولة الراوي (179) - فترة الطفولة وماضي سامر (IVI) -حوارات الراوي مع أمينة (ro9) 
في هذه الأمثلة يعود المؤلف الى الماضي ويروي ذكرياته للفترة الماضية ـ ويتبين في كل هذه السردية أن القاريء يعود الى ذكريات الماضي الخاصة بنفسه هو وبسائر الشخصيات والايام التي رواها والأحداث التي وقعت في ذلك الزمان والآن، فقام برواية تلك الأحداث لمخاطبيه وقارئيه. ما يقوم به المؤلف من إسترجاع الماضي يمثل في واقع الامر إشارات دقيقة وعينية تخرج الرواية

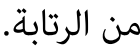

الخلاصة

هي حالة في السردية ، توضح فيها استمرار وتوالي الأحداث على أساس تقرير مضغوط ومتراكم. ففي الخلاصة، نحصل على زمان القصة من خلال الضغط ومراكمة النص؛ أي أن زمان الخطاب يكون أقصر من زمان القصة. وطبيعي أن درجة مراكمة وضغط كل خلاصة تكون متغيرة مقارنة بخلاصة اخرى (تودورف، rشسا: • · ). برينس يتحدث أيضا عن وجود نوعين من خلاصتين. فهو يرى: أنه في خلاصة النوع الاول تعرض فقط بعض الخصائص لعدة خيوط من الأحداث المختلفة وأما في خلاصة النوع الثاني يتم فيها فقط عرض خصائص مشتركة لعدة خيوط للأحداث بصورة متساوية . فيروي خلالها ما جرى عدة مرات من الأحداث مرة واحدة فقط. وهذا النوع من الخلاصات يطلق عليه اسم السرد

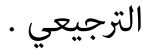

في رواية الزمن الموحش ينقل الراوي بعض الأحداث التي وقعت عدة مرات، مرة واحدة فقط وهو ما يؤدي الى زيادة السرعة السردية. فهو يكرس بذلك كمية ضئيلة من النص لأحداث متكررة كثيرا في القصة. والاستفادة من اسلوب السردية هذا يسمح بمرور قسم كبير من زمان

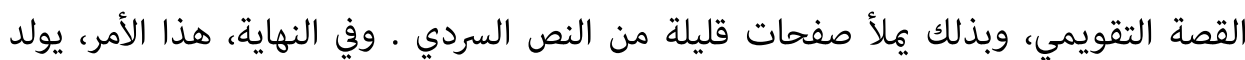

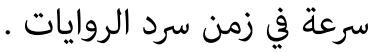
ويتضح لنا من خلال دراسة هذه الرواية أن الأحداث جرت عمليا (واقعيا) مرات عديدة ، لكن المؤلف لم يبينها سوى مرة واحدة خلال سرد الرواية ـ وإننا نشاهد على سبيل المثال إن المرات التي التقى فيها الراوي شخصيات مثل أمينه و راني و ديانا هي أكثر بكثير مما تحدث

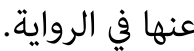


التوسعة وتعني أحتواء قسم طويل من العمل السردي الذي حصل بشكل سريع ـ لكن راوي الزمن الموحش مل يستفد كثيرا من عنصر التوسعة بل قام على العكس من ذلك بخلاصة أقسام

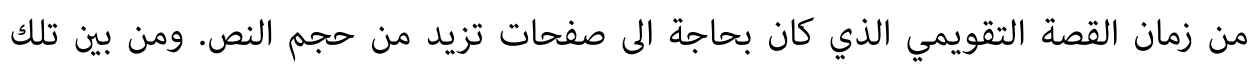

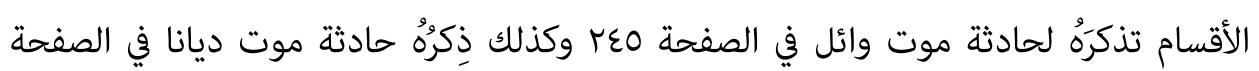
r والتي إختصرها المؤلف بشدة.

النتائج

في هذا البحث، جرت دراسة العوامل المؤثرة في تسارع أو تباطؤ السرعة السردية في الزمن الموحش • وأظهرت دراسة مراحل السرعة السردية في رواية (الزمن الموحش)) هُن التسارع والتباطؤ في السرعة السردية كان له التأثير المباشر في العلاقة مع المخاطب وإنجذاب لأحداث الرواية في هذا الكتاب. فمن جهة قام المؤلف في هذه الرواية بحذف الكثير من الأحداث المتكررة التي تحتل حيزا من الزمان، وهو ما أدى الى إيجاد أكبر سرعة كما استفاد من جهة اخرى من هن

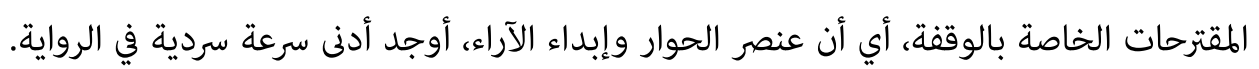
كذلك فان وجود الوصف و استعادة احداث الماضي تعد من العوامل المؤثرة في إيجاد العلاقة الزمنية المتعادلة بين القطعة السردية مع أحداث أعيد تمثيلها ومن بين انواع السرعة السردية، فأوجدت مشهد (السرعة السردية المتوازنة). وعليه فان المؤلف، استخدم التقنيات الزمنية المختلفة،لإسباغ السرعة على أقسام من الرواية للتخفيف عن كاهل القاريء(مثال: إنه مل يذكر كافة لقاءاته مع أمينه و راني ومُنى و ديانا و سائر الشخصيات) وفي أقسام اخرى ، خفف من السرعة السردية ، وعليه فإنه يمكن القول : إن إن إنهاء السردية في هذه الرواية من البداية وحتى النهاية، فيها تناوب في السرعة ـ ونظرا لهذه الملاحظة من المقترحات المتعلقة بعنصري الوقفة والمشهد أي في الحوار والوصف وإبداء الرأي وإستعادة فئاد الماضي تشكل القسم الأكبر من هذه الرواية ،ذلك إن خفض سرعة السرد هو أكثر شيء نشاهده في هذا الرواية. 
وبذلك يكون حيدر حيدر قد إستفاد من التمهيدات والحيل الروائية من قبيل (التناوب والتضمين والتداخل بين المشاهد) في جعل الرواية مستعدة لقبول مختلف أنواع السرعة السردية وهذا الأمر كان له أبعد الأثر في إثراء هذه الرواية فضلا عن إظهار مايتحلى به هذا الكاتب من فن رفيع مقارنة بسائر المؤلفين. وعليه فإنه نظرا لنتائج هذه المقالة يكن إعتبار رواية الزمن الموحش في المجموع، بأنها نص روائي يتميز بالسرعة السردية البطيئة. كثرة التناوب في هذه الرواية بلغت حدا نشاهد فيه أن الراوي يتخلى عن خط محدد في القصة ويقوم بتوضيح سطر من خط قصة اخرى وذلك بشكل تتداخل فيه خطوط القصص مع بعضها من دون أية مقدمات ومن دون أية علامات ويعتبر هذا من الاسباب التي تصيب القاريء بحالة من الإلتباس والحيرة.

كذلك نشاهد الكثير من حالات التداخل في رواية الزمن الموحش. فهي تروي لكل شخصية ماضيها و قصتها وبذلك يحصل تداخل قصصي في القصص الاخرى وخاصة عندما يحصل اختلاف في زمان القصص التي جرى فيها هذا التداخل مع زمانالسردية.

المصادر

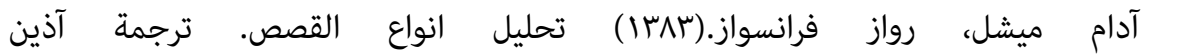
حسينزاده، كتايون شهبرراد، طهران:قطره.

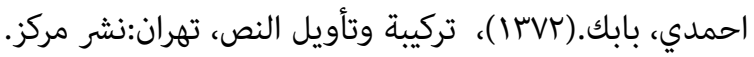

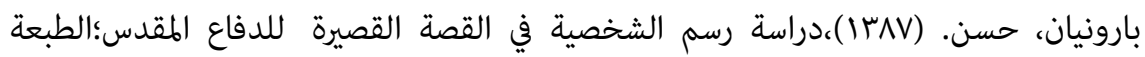
الاولى، تهران: مؤسسة حفظ الآثار ونشر قيم الدفاع المقدس.

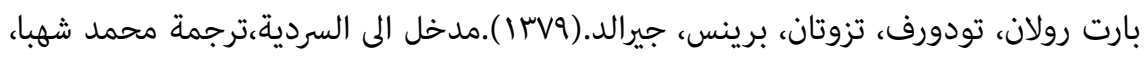
تهران:هرمس.

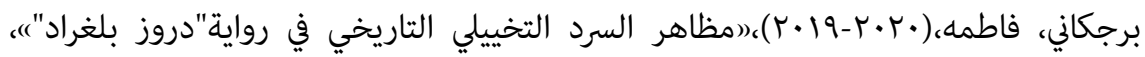

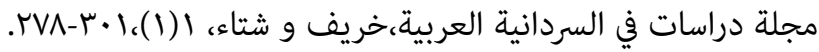
برينس، جبرالد.(اوبـا). السردية شكل وفعل السردية، المترجم محمدشهبا، الطبعة الثانية، دار نشر مينوى خرد. 
• جينت، جيرار.(199V). خطاب الحكاية؛ ترجمه محمد معتصم و الاصدقاء ،الطبعة الثانية،

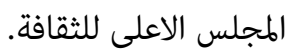

تودورف، تزوتان. (rیז1). التعابير البنيوية؛ ترجمة محمد نبوي، جr، تهران: آكه.

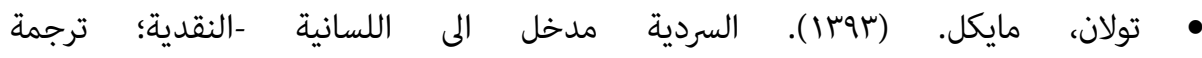

السيدة فاطمة علوي والدكتورة فاطمة نعمتي، تهران: مؤسسة دراسة وتأليف كتب العلوم

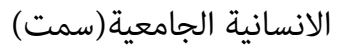

جشمه عميرى،صبح. (جسعا)رسالة (بنية الشخصية فى رواية وليمة أعشابالبحر)؛جامعة

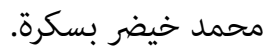

سرباز، حسن و رسول نجاد، عبدالله و خسروي زاده، سودابه. (عوبار).زمانالاضطراب في

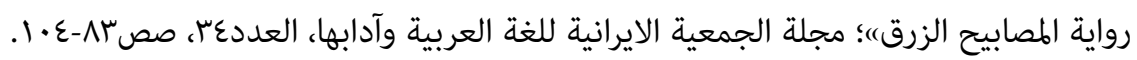
صافي، حسين. (عوبار). الإدراك في الأدب القصصي : النهج اللغوي؛ تهران:سياه رود. ريمونكنان، المعاصرة ؛ ترجمة ابوالفضل حري، تهران: انتشارات نيلوفر. لوته، ياكوب. (MMrاI). مقدمة السردية في الادب والسينما؛ ترجمة اميد نيك فرجام، تهران:

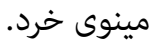

مدني بور، شهريار.(r/ץ!). كتاب ارواح شهرزاد( الجديد من الحيل وأشكال، القصص الحديثة؛ الطبعة الاولى ، تهران:ققنوس. مكلى، رابرت. (IINVV). القصة البنيوية، أفاط واسس كتبة السيناريو)؛ ترجمة محمد آلهد كذرآبادي، الطبعة الثالثة، طهران:هرمس. رابر. مندولا، آ.آ(199V).الزمن و الرواية؛ ترجمه بكر عباس، الطبعة الاولى،بيروت:دارصادر.

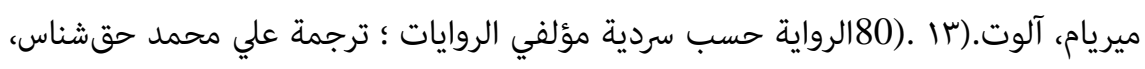
تهران:نشر مركز. والاس، مارتين. (ا9ج|). نظريات السردية، ترجمة محمد شهبا،طهران:هرمس. يعقوب، ناصر.(1.بr). الرواية و التشكيل(دراسة فى فنّ الجمال ناجى الرّاوى)؛ الطبعة الاولى، بيروت: المؤسسة العربية للدراسات و النشر. 


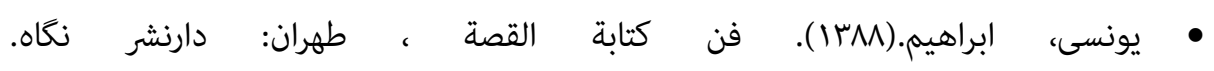

\section{References}

- Adam Michel, Roaz Francoise (1383) Analyzing the types of stories. azan translation Hosseinzadeh, Katayoun Shahparrad, Tehran: Qatra.

- Ahmadi, Babak. (1372), the structure and interpretation of the text, Tehran: Center publication.

- Baronian, Hassan. (1387), A study of character drawing in the short story of the Holy Defense, first edition, Tehran: Foundation for Preserving Antiquities and Spreading the Values of Holy Defense.

- Bart, Roland, Todorf, Tzutan, Prince, Gerald. (1379). Introduction to Narrative, translated by Muhammad Shahba, Tehran: Hermes.

- Bourjakani, Fatima, (2019-2020), "Manifestations of the historical fictional narration in the novel "The Druze of Belgrade", Journal of Studies in Arabic Sardaniya, Autumn and Winter, 1 (1), 301-278.

- Prince, Gibrald (1391). Narrative, the form and verb of narration, translated by Muhammad Shahba, second edition, Minawi Khurd Publishing House.

- Gent, Gerard. (1997). Storytelling letter; Translated by Muhammad Mutasim and the Friends, Second Edition, The Supreme Council of Culture.

- Todorf, Tzutan. (1382). structural expressions; Translated by Muhammad Nabawi, Ch. 2, Tehran: Ah.

- Tolan, Michael. (1393). Narrative is an introduction to linguistic-critical; Translation Ms. Fatima Alawi and Dr. Fatima Nemati, Tehran: Foundation for the Study and Authoring of University Humanities Books (Samt)

- Jashmeh Amiri, Subh. (1436) Thesis "The Structure of Personality in the Novel of the Seaweed Banquet"; University of Muhammad Khider, Biskra.

- Sarbaz, Hassan and Rasool Nejad, Abdullah and Khosravizadeh, Sudaba. (1394). The time of turmoil in the narration of the blue lamps"; Journal of the Iranian Society of Arabic Language and Literature, Issue 34, pp. 83-104.

- Safi, Hussein. (1394). Perception in fiction: a linguistic approach; Tehran: Siah Rod.

- Rimonkanan, Shlomit. (1387). Narrative Narrative: Structural Expression contemporary; Translated by Abolfazl Hurri, Tehran: Nilofar publications.

- Lotte, Jacob. (1388). Introduction to narrative in literature and cinema; Translated by Amid Nik Farjam, Tehran: Minavi Khord.

- Madanipour, Shahryar (1383). The Book of Scheherazade's Spirits (The new book of tricks and forms, modern stories; first edition, Tehran: Qaqnus).

- McCully, Robert. (1387). Structural story, patterns and foundations for screenwriters); Translated by Muhammad Ghazarabadi, third edition, Tehran: Hermes.

- Mandola, AA (1997). Time and Novel; Translated by Bakr Abbas, first edition, Beirut: Dar Sader. 
- Miriam, Allot (1380). The novel according to the narration of the authors of the novels; Translated by Ali Muhammad Haqshanas, Tehran: Center publication.

- Wallace, Martin. (1391). Narrative Theories, translated by Muhammad Shahba, Tehran: Hermes.

- Yacoub, Nasser. (2001). Narrative and Formation (A Study in the Art of Beauty by Naji Al-Rawi); First Edition, Beirut: The Arab Institute for Studies and Publishing.

- Younesi, Ibrahim (1388). The Art of Writing a Story, Tehran: Darnashr Negah. 


\section{مطالعات روايت شناسى عربى}

شايا جايى: PGVG-VVF

بر رسى سرعت روايت در رمان الزمن الموحش بر اساس نظريه روايتشناسى جرالد يرينس azarshab@ut.ac.ir

رايانامه: محمد على آذرشب

T_heydari@sbu.ac.ir

استاد زبان وادبيات عربى، دانشكده ادبيات و علوم انسانى، تهر ان، ايران. رايانامه:

طاهره حيدرى

استاديار و هيئت علمى زبان و ادبيات عربى دانشكاه آزاد اسلامى كرج، ايران.

جكيده

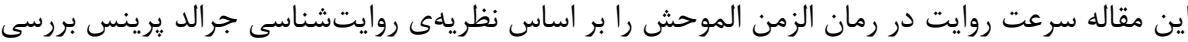

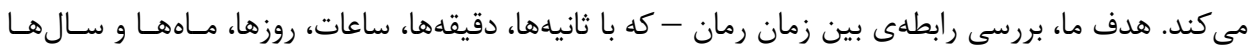

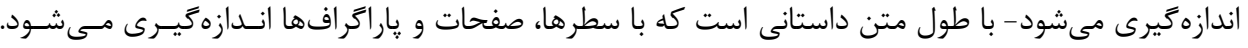

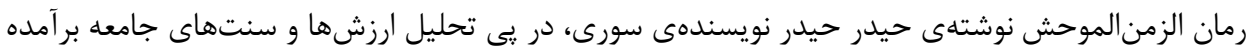

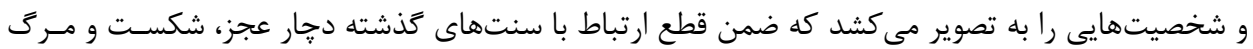

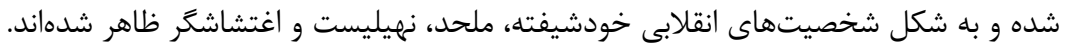

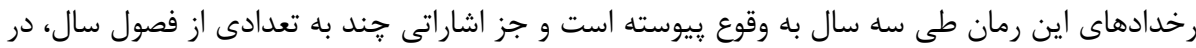

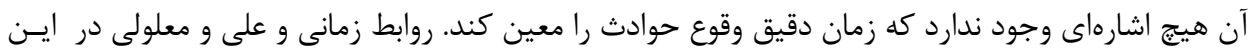

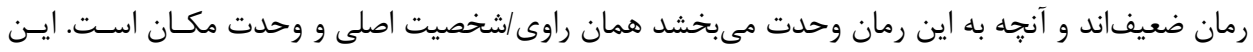

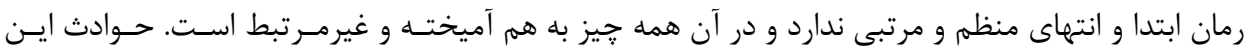

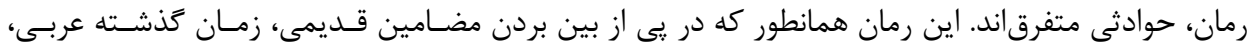

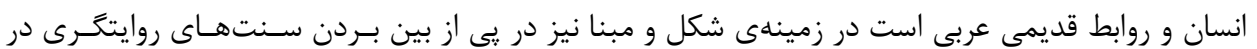

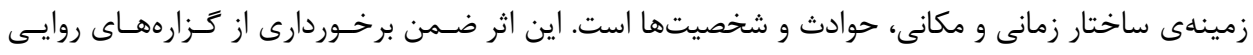

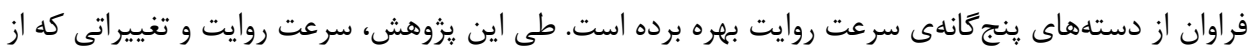

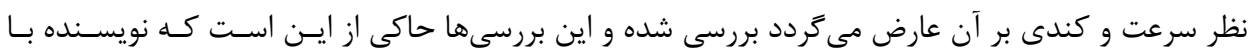

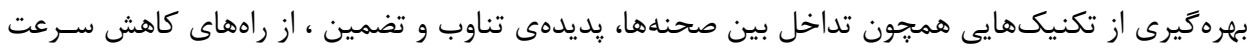
روايت، استفادهى حداكثرى كرده است. وازَّان كليدى: حيدر حيدر، الزمنالموحش، روايتشناسى، زمان روايى، جرالد برينس 


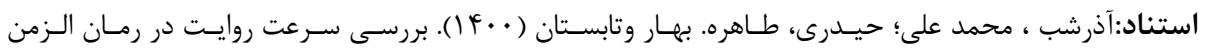

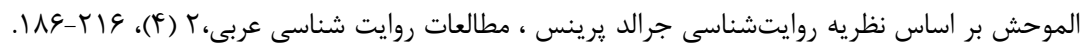

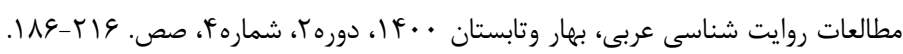

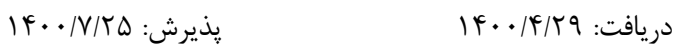

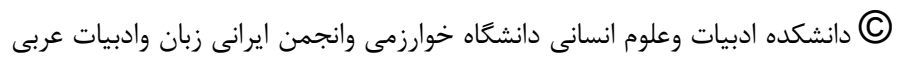

